\title{
LECTURA DE LOS «RELATOS DE VERDAD» EN EL SIGLO XVIII: DE LAS CAUSAS CÉLEBRES AL SUCESO CRIMINAL
}

\section{Laura Serrano de Santos}

Los estudios dedicados al emplazamiento teórico de la crónica de sucesos en su particular definición paraliteraria tuvieron sus inicios en las líneas preteóricas de Merleau-Ponty (1960) en 1954, que se vieron pronto secundadas por las distintas aportaciones de Seguin $(1956,1959,1965,1982)$ que emparentaba esta forma de narración con el romance de ciego y el folletín.

Con Roland Barthes (1962) la crónica de sucesos alcanzará una de las más rigurosas calificaciones y su estructura quedará fijada de tal modo, que dejará el campo lo suficientemente abonado para las matizaciones y desarrollos de posteriores investigaciones: Auclair (1963, 1966, 1970, 1982), Schulmann (1971: 244-252), Burgelin (1974: 98-103), Christin (1973), Aubague (1980), Sorbier (1983), Lecerf, ed. (1981), Monestier (1982-1983, 1986), Frandon (1984) y Serrano de Santos (1994).

Sin embargo, entre las puntualizaciones recibidas por el llamado por nosotros suceso criminal ${ }^{1}$, hay un destacado grupo de estudios proce-

1 Suceso criminal es la forma de narración cuya lectura literaria (si bien, en este caso, paraliteraria) la dota de tal rango. Establecemos así una diferencia de perspectiva 
dentes de especialistas en cuestiones literarias que atañen al siglo XVIII cuya enjundia para nuestro objeto de estudio, así como para la iluminación del fenómeno literario en general, ha sido la responsable de que su comentario sea el centro y propósito de este artículo, pues muchas de las contribuciones teóricas al suceso criminal han venido de caminos cercanos a él: causas célebres, ejemplo, anécdota, novela trágica, folletín, etc.

Con este motivo se comentarán aquí los valiosos trabajos de Sgard (1974: 459-470), Favre, Sgard y Weil (1978: 199-225), Moureau (1978: 126-134), Lever (1979: 577-593), Jechova (1980: 3-18), Lüsebrink (1980: 153-162), Rimbault (1981), Thiesse (1981) y Nies (1986: 184-196).

Jean Sgard (1974: 459-470), especialista en literatura neoclásica, se ocupa de la figura de Gayot de Pitaval y de su obra Causes célèbres et intéressantes avec les jugements qui les ont décidées (1734) ${ }^{2}$. Para empezar, constata cómo en la concepción que se tiene de literatura hasta el siglo XVIII, se había excluido la historia verdadera (Sgard, 1974: 469); esto es obvio para la Teoría de la Lectura Literaria (Cabada Gómez, 1994), puesto que, hasta la revolución romántica y su consiguiente lectura literaria de la escritura como expresión, primaba la lectura aristotélica, que lee la escritura como imitación, discerniendo lo literario (a la sazón, poético) como imitación de lo histórico (Cabada Gómez, 1992: 83-92).

Sin embargo, Sgard (1974: 468) reivindica para las causas célebres, no un estatuto de literatura popular o infraliterario, sino la reflexión sobre la posibilidad de un título plenamente literario. Las razones para tal adscripción no son otras sino la propia labor de Gayot de Pitaval. Éste asocia, según Sgard (1974: 459), dos formas de narración aparentemente contradictorias: la relación popular y la exposición jurídica. Pero el quid de tal literariedad está según Sgard (1974: 465) en que

notre conteur va donc imiter la nature dans la mesure où celle-ci imite le roman; il va retrouver dans la réalité les archétypes du récit, essentiellement ceux de la nouvelle tragique.

con el marchamo crónica de sucesos que en el ámbito de la comunicación (y no de la literatura) recibe una lectura histórica en cualquiera de sus variantes: ideológica, sociológica, política, jurídica, etc. (Serrano de Santos, 1994). Por otro lado, especificamos nuestro interés en el tipo de suceso criminal, dejando por el momento a un lado el prodigioso (cfr. Barthes, 1962: 228).

2 Gayot de Pitaval y A. Fouquier son considerados como modelos por Caro Baroja (1969: 186) de lo que luego serán las causas célebres españolas (cfr. asimismo Ferraz Martínez, 1992: 720-722). 
Así, si hasta el siglo XVIII sólo era literario (en tanto poético) lo imitativo, Sgard lo que trata de hacer es describir las causas célebres como imitadoras de la imitación, que no otra cosa era la novela trágica. Por ello, este artículo de Sgard es particularmente valioso porque nos introduce en la consideración literaria de un género - las causas célebres ${ }^{3}$ - que, al igual que el suceso, había sido apartado de la Historia de la Literatura por las convenciones de la propia Literatura. A pesar de que actualmente no prime la lectura clásica, sino la moderna (que lee como ficción) (Cabada Gómez, 1992, 1994) ${ }^{4}$, el acierto de Sgard (1974: 465) reside en que, desde el siglo xx (lejos del xviII y libre de la mímesis aristotélica), propugna la consideración literaria de las causas célebres aduciendo razones del más clásico cariz imitativo, si bien en versión quintilianista; y ello se debe a que Sgard se refiere directamente 'a Pitaval que sí es del siglo XVIII y, por tanto, todavía se halla circunscrito a las convenciones miméticas.

Otra estudiosa que va a proseguir estas consideraciones acerca de Pitaval y sus Causas célebres va a ser Hana Jechova (1980: 3-18), que mantiene que las relaciones de sucesos, causas célebres o crímenes sensacionales se presentan en el siglo de las luces como documentos puros con pretensiones moralizantes. A pesar de lo cual, sigue Jechova, la literatura comienza a penetrar en esos documentos de forma que, en algunos casos, es dificil establecer una frontera entre lo documental y lo literario (cfr. Lever, 1979: 578) quedando en la incertidumbre. Pese a ello, Jechova pretende en su artículo mostrar la literarización ${ }^{5} \mathrm{de}$ algunos de estos sucesos. No se puede olvidar -Jechova (1980: 4)que en el siglo XVIII es el hombre en sí mismo lo que impera; por ello, su comportamiento es formado y determinado por las circunstancias en que se encuentra ${ }^{6}$. Se une a esto el interés que causa en el siglo

3 En España, Ferreras (1972: 259-313), sin embargo, califica la novela de crímenes como «uno de los productos más simplificados de la paraliteratura» y se refiere a las Crónicas de Tribunales (aparecidas en España un siglo más tarde que en Francia), considerándolas «reales historias del suceso» que «intentan comunicar periodísticamente los crímenes reales que acontecen en el mundo». No obstante, reconoce que «el crimen real se hincha periodísticamente, como se hinchan las catástrofes, los accidentes, los suicidios: estamos ya, y en pleno siglo XIX, en plena sección de sucesos». Ahora bien, Ferreras no especifica si su catalogación paraliteraria es actual o histórica.

4 Al hablar de las convenciones de la propia LITERATURA desde hoy, es claro que nos estamos refiriendo a su LECTURA. Por esta razón, no se puede echar en olvido como dice Cabada Gómez (1982: 10) que «una forma de lectura es un factor, dentro del funcionamiento literario de una sociedad, al que se puede considerar coproductor de literatura, pues coopera en la producción de una obra con su significado».

5 Cfr. Botrel (1993: 173) cuando se refiere en idénticos términos al «proceso de literaturización del suceso».

6 Estas ideas del más puro estilo rousseauniano dejaron una huella de considerable percepción hasta hoy, ya que muchos de los postulados neoclásicos todavía perduran. La 
XVIII todo lo excepcionalmente humano, máxime cuando se toma como verdadero. Precisamente, Pitaval (cfr. Sgard, 1974: 459-470), autor de las Causas célebres (1734), deja constancia del rechazo humano por lo falso de la «más bella ficción y de la atracción placentera por lo verdadero cuando se une a lo maravilloso" (Jechova, 1980: 8). Rehusando la ficción en nombre de la veracidad - sigue Jechova-, Pitaval quiere dar al público un nuevo tipo de lectura: relatos sensacionales que representan hechos fuera de lo común; y todo ello se justifica por la autenticidad de tales eventos. En contra de sus intenciones, Jechova (1980: 9) encuentra la literarización de las Causas célebres cuando su autor las compara con las bellas tragedias (;Qué difícil es escaparse de la Literatura! o como diría Barthes, del Lenguaje; cfr. también Burgelin, 1974: 100). En este momento el autor sitúa dichas causas reales (es decir, históricas) en el contexto de lo literario, aunque su primer interés es la moralización de dichas historias y su resolución jurídica.

Más tarde, en 1792, August Gottlieb Meissner imita a Pitaval en Alemania ${ }^{7}$ con Auszüge aus Kriminal-Akten und Geschichten con la diferencia —dice Jechova (1980: 12) — de que éste hereda el espíritu de Pitaval, pero situando estas historias en otro nivel de lectura. No se dirige Meissner a los aficionados a la jurisprudencia, sino a un extenso público ávido de novedades... literarias ${ }^{8}$.

Mientras que Pitaval no ofrecía retratos de los personajes, sino cuadros judiciales, Meissner se interesa por la psicología del criminal, juzgando a éste como inocente, siendo la sociedad la responsable de la formación del individuo (Jechova, 1980: 13). De esta manera, Meissner reemplaza el documento por una ficción de tesis, mezclando los sucesos sucedidos con motivos lacrimógenos e inverosímiles. La disolución,

irresponsabilidad del hombre trae consigo importantes consecuencias: en lo literario, por ejemplo, se va difuminando el héroe y el malo deviene en enfermo o marginado. Como dice E. Sullerot (1970: 137): «La responsabilité est attenué, Satan ayant des complexes".

7 Cfr. este proceso con el del autor propio de la lectura clásica (imitativa, poética y verosímil) que se constituye genérica por cuanto acrecienta el caudal de lo ya aportado (Cabada Gómez, 1994: 168-172).

8 Análogamente, Ferreras (1972: 229) cuenta cómo en el s. XIX, Vicente Caravantes publicó entre 1859 y 1861 sus Anales dramáticos del crimen o Causas célebres españolas y extranjeras con el siguiente resultado: «Con Caravantes, y dada la preparación o especialidad del autor, los crímenes adquieren carta de naturaleza en la novela por entregas; desgraciadamente la obra debió de tener gran éxito y las imitaciones y vulgarizaciones van a abundar a lo largo de los años. Si Caravantes se cuida del aspecto jurídico del crimen, sus imitadores y secuaces van a preocuparse únicamente de la descripción del mismo». La cursiva es nuestra y es utilizada para llamar la atención sobre el proceso (para) literario a partir de la imitación de lo pretendidamente histórico. 
la frontera, la elección es, en último caso, del lector. Considera Jechova (1980: 14) que se puede disfrutar de los documentos tomándolos como literarios y se puede leer también literatura no como verosímil, sino como auténtica (lectura histórica).

La importancia del artículo de Hana Jechova es fundamental no sólo por abordar la literariedad del suceso criminal, sino por hacer responsable a la acción conjunta de texto y lectura (cfr. Cabada Gómez, 1980, 1981, 1982, 1989, 1992, 1994).

Siguiendo con la exposición de estos estudios neoclásicos, tomamos el que elabora Sgard en colaboración con Robert Favre y Françoise Weil (1978: 199-225) en el cual se ocupan de lo ajustado al término fait divers en 1734. Sabido es que tal concepto no existía en el siglo XVIII (como es mencionado en Romi, 1962; Seguin, 1965, y Auclair, 1982, ya que no se constata hasta 1863 con la aparición del Petit Journal) y, sin embargo, según Favre, Sgard y Weil, es posible la mención de otros términos de cierta equivalencia en la Gazette d'Amsterdam, en Le Pour et Contre de Prévost (que nutrirá al Mercure Suisse), así como en Anecdotes et Lettres Secrèts. Estos sustantivos son los siguientes (Favre, Sgard, Weil, 1978: 200):

1) Fait avérés, phénomenes que dan cuenta de prodigios, esto es, de lo imposible verdadero.

2) Caractères et exemples, que sirven de pretexto a un comentario moral. Dan cuenta de lo posible.

3) Relations, aventures, anecdotes, histoires: todas ellas son probadas (avérés), localizadas y datadas y, a pesar de ello, se remiten a lo literario.

Estas tres clases de sustantivos denotan el carácter histórico e informativo de la narración del hecho (avéré, récent, nouveau) o el carácter excepcional (extraordinaire, singulier, admirable); también anuncian la emoción que se habrá de suscitar (effrayant, horrible, tragique, plaisant, merveilleux). A partir de estas denominaciones, y puesto que el canard se registra ya en el ámbito de lo literario gracias a su introducción en la Institución por estudiosos como Seguin (1956, 1959, 1965, 1982, 1983), Botrel (1993), Caro Baroja (1969, 1986), Marco (1977) o García de Enterría (1973, 1983), probarán cuán cerca del canard se hallan las noticias dadas por el abate Prévost por cuya proximidad merecen la categoría de literarias.

El suceso como construcción, como producto fabricado, es evidente para estos autores (Favre, Sgard, Weil, 1978: 207) y, desde Pitaval, 
pimer conservador de sucesos, se puede considerar que sus causas célebres, junto con las noticias de Prévost, son portadoras de dos principales funciones: reguladoras del discurso social y, a la vez, vehículos de lo lúdico. Esta última consideración del suceso como entretenimiento, le confiere la categoría genérica (Favre, Sgard, Weil, 1978: 211) ${ }^{9}$ puesto que para ello se ha de tener muy en cuenta el papel del lector (Favre, Sgard, Weil, 1978: 213); si bien Sgard (1974) postulaba en su artículo anterior una reflexión sobre la literariedad de las causas célebres de Pitaval (apoyada firmemente por Jechova, 1980), aquí los tres autores califican abiertamente como literarias las causas de Pitaval y las noticias de Prévost.

La figura de Charles Dufresny, dramaturgo neoclásico, va a constituir el punto de atención de François Moureau (1978: 126-134) que en su artículo reflexiona sobre la verdad y la verosimilitud de lo que llama ciertos soportes de realidad cuales son los sucesos. La dedicación de este autor a los sucesos viene dada a través del dramaturgo Dufresny que estuvo a cargo de una de las publicaciones literarias más antiguas de Francia, creada en 1672. Da cuenta Moureau de la cantidad de relatos de creación que se dan como transcripciones de lo real (Moureau, 1978: 127). Aparte del hecho de las diferentes versiones que los narradores hacían de distintas noticias o relaciones, la ambigüedad de la creación también se encuentra en el contraste que se produce entre las precisiones de lugar y tiempo y la convención de los nombres galantes atribuidos a los personajes de dichas noticias. Dufresny es consciente -dice Moureau (1978: 132) - de que la exaltación del suceso, de la narración del pequeño hecho verdadero, conduce directamente a lo literario. Aunque se trata de un brevísimo artículo, su interés radica en la constatación temprana que hace Dufresny acerca de la incorporación de la verdad como verosímil (Moureau, 1978: 131).

En un posterior trabajo Moureau (1980: 19-28) presenta la siguiente definición de suceso: «le fait divers $n^{\prime}$ existe ${ }^{10}$ que par le récit qu'on en donne: il est signe». Lo cual no hace sino retomar la postura de Barthes (1962). Señala, además el valor pedagógico que emparenta los exempla con los canards o con las gacetas del Antiguo Régimen francés y estudia las distintas versiones acerca de un suceso que narró las atrocidades sexuales del marqués de Sade a una joven viuda. El tratamiento de exemplum que recibió este relato queda puesto de manifiesto por

9 Del mismo modo, Botrel (1993: 173) habla de la «función estética y social que puede tener el sucesom.

10 La cursiva es nuestra. 
Moureau (1980: 22), que, además, muestra cómo se recuperó el suceso y, por ello, cómo lo real histórico encuentra sus primeros autores literarios mediante los procedimientos de elaboración de la verosimilitud. Es asimismo sugerente ver cómo en el tratamiento de este suceso, se compara a Sade con un ya personaje folclórico al que de nada le vale su reciente rehabilitación histórica (como persona): Gilles de Rais, Barba Azul ${ }^{11}$.

Si Sgard (1974) y Jechova (1980) reflexionan sobre el suceso por la vía de las causas célebres, Maurice Lever (1979) hace lo propio atendiendo a las Historias Trágicas de François de Rosset, el primer traductor en Francia de la obra cervantina. El título de este artículo nos basta para su consideración literaria; particularmente nos causa interés porque desde él se observa ya un desplazamiento de un ámbito a otro bien distinto. Dice así: «De l'information à la nouvelle: les canards et les histoires tragiques de François de Rosset». Aboga en él por la consideración plenamente literaria de un gran número de relatos que tienen su origen en un hecho real como los crímenes, las inundaciones, etc., y que se mezclan con detalles inventados y exagerados formando una mixtura difícil de separar. Una gran parte de estos sucesos (los denomina faits divers avant la lettre) comportan una función moralizante que permite que el suceso sea utilizado como parábola. Según esto, se puede ver el estrecho parentesco con los exempla y, además, el hecho de que Rosset sea el primer traductor de las Novelas Ejemplares de Cervantes, deja de ser una casualidad para significarse como la continuación de todo un punto de vista que concibe la narración de lo real histórico con una función utilitaria que hace, al mismo tiempo, que este uso moralizante (bajo el signo del prodesse horaciano) desborde el hecho en sí. Esto ocurre cuando del relato con moraleja se pasa a la moraleja por el relato. Ya se había visto esto al tratar de los usos narrativos de Pitaval, el abate Prévost o Meissner (Sgard, 1974; Favre et alii, 1978, Jechova, 1980).

Lever (1979: 579) cuenta que la máxima atención era la suscitada por el canard de información (nótese la confluencia de literatura e his-

11 El 9-11-1992 un tribunal de honor formado por nueve miembros rehabilitó la figura de Gilles de Rais, Barba Azul. Entre esos miembros figuraron el escritor Gilbert Prouteau; el presidente, Henri Jurany; el historiador, Henri Laborit, y el ex ministro, Michel Crépeau, que pidieron al Presidente de la República, François Mitterrand, y al primer ministro, Pierre Bérégovoy, «el restablecimiento absoluto de la verdad histórica» (Hermoso, 1992: 26). Pero ¿acaso puede borrar la Historia 500 años de Literatura máxime cuando se sigue confundiendo a Rais con Barba Azul porque se ajusta a un anterior tipo construido (ver Monestier, 1988: 52)? 
toria) unido a la noticia marcada como funesta, deplorable, lamentable, espantosa, heredada del italiano Bandello cuyas Historias Trágicas causaron furor en la Francia de 1559 con la consiguiente imitación de Joseph de la Mothe, Jean Prévost, Jean d'Intras, Tourniol, Nervèze y otros. Cuando Rosset elabora en 1614 unas Historias Trágicas al modo de Bandello, Lever nos relata cómo Rosset adapta a los usos y costumbres de la época canards antiguos. De esta atemporización y literarización en función del gusto del público, Lever (1979: 587) extrae las siguientes conclusiones: el poder de Rosset no es, ni más ni menos que el poder de re-crear una verosimilitud literaria a partir de una información dada como verdadera. Esta verosimilitud (en el particular género de la novela trágica) consiste - prosigue- en producir misterios, en sugerir la presencia de fuerzas oscuras y amenazadoras ${ }^{12}$, en hacer admitir lo excepcional en la lógica del relato produciendo un frisson nouveau (Lever, 1979: 587). De esta manera, este autor sitúa la historia trágica en un terreno en el que confluyen a la vez suceso y novela, terreno en el que, por ende, se encuentran verdad informativa y verosimilitud literaria. Por consiguiente, Lever (1979: 593) juzga la historia trágica como la codificación de la información mediante estereotipos de la narración en cuanto imitación literaria; no de otra manera queda exorcizada la información, sino a base de que la insistencia de verdad se constituya como señal de artificio ${ }^{13}$.

Esta utilización de lo auténtico para la contemplación del relato en tanto que literario, se vuelve a encontrar en un artículo del alemán Fritz Nies (1986: 184-196), en el que abunda en la demanda de información por parte de las masas que dé más la impresión de autenticidad que las novelas realistas ${ }^{14}$. Por ello los periodistas crearon un tipo de textos al que denominaron sucesos en los cuales el redactor somete las noticias sensacionalistas a un tratamiento meticuloso (cfr. Auclair, 1966 o Christin, 1973: 55-56) quedando fijada una forma de narración que aún pervive.

Dicho tratamiento de la autenticidad es tan artificial hoy como en el siglo XVIII. Así nos lo describe Hans-Jürgen Lüsebrink (1980: 153-162)

12 Cfr. Barthes (1962) y Auclair (1982: 63-90) a propósito de los conceptos de enigma y suspense.

13 Ferreras (1973: 249-261) cita un único caso de un imitador de estas historias trágicas en España. Se trata de Agustín Pérez Zaragoza Godínez, que en 1831 (¡cuánto retraso desde Bandello (1559) o Rosset (1614)!) publica Galería Fúnebre de Historias Trágicas. Siguiendo la tradición, el autor, «insiste constantemente en la veracidad de las novelas que siguen" y aludiendo a la ejemplaridad de las mismas sostiene que «todos los medios son buenos cuando se encaminan a purificar las costumbres».

14 Por cuya lectura literaria romántica (cfr. Cabada Gómez, 1994) habían dejado de percibirse como relatos verdaderos en cuanto verosímiles. 
en un artículo dedicado al tratamiento de los crímenes sexuales en las causas célebres del siglo de las luces. El autor hace hincapié en la construcción artificial por parte de Pitaval de hacer coincidir el universo representado y el discurso de la enunciación que se erige, a su vez, representante de la sociedad entera (Lüsebrink, 1980: 157). Este proceso no es, sino una labor de re-escritura que comporta operaciones de diversa índole cuales son: la puesta en relato del hecho mismo, la traducción del lenguaje jurídico especializado a un lenguaje accesible para el gran público, la culturalización e ideologización del hecho en el discurso del narrador, etc. Todos ellos son mecanismos responsables de hacer leer el enunciado del narrador como un discurso de verdad (cfr. efecto de realidad de Barthes, 1968: 84-99).

Caroline Rimabult (1981) distingue el suceso de la anécdota por el carâcter de exactitud y verosimilitud del primero al ofrecer la indicación del lugar y la fecha (hipotiposis de Barthes) y ofrece estadísticamente la cantidad y temática de los sucesos que aparecen en las distintas publicaciones femeninas del siglo XVIII. En las siguientes líneas (Rimbault, 1981: 152) alude a cuestiones tan centrales como son lectura, literatura y catarsis:

La lecture d'un fait divers est un divertissement qui fait trembler; crimes, accidents, cataclysmes, bêtes féroces forment le lot commun d'une information féminine que parle à l'imagination plus qu'à la consciènce des femmes.

Además, ve en el suceso una ejemplaridad y moralidad que vuelven «l'horreur douce et la misère digne». El hecho de la procedencia real (histórica) del suceso no se le oculta a Rimbault (1981: 153) que lo considera como pretexto (los formalistas rusos dirían motivación) para algo que no es sino artificial:

Le fait divers attire plus pour ce qu'il fait imaginer que pour ce qu'il dit réellement; la connaisance de l'événement n'est plus qu'un alibi!

Por último, Anne-Marie Thiesse (1981: 133) constata la sorprendente similitud de técnicas narrativas y presentación entre los sucesos y el folletín: los adjetivos estereotipados, el efecto sorpresa, los títulos (cfr. Auclair, 1966). Cuando un suceso criminal crea tal efecto de suspense que se sucede durante varios días (a veces semanas) rebasándose el 
hecho en sí y manteniendo la expectativa mediante el consabido continuará, se estrecha el parentesco con la novela folletinesca ${ }^{15}$. De hecho, la lectura de un suceso puede provocar la exclamación: «¡Es un verdadero folletín!» $y$, a la vez, el autor de folletines aprovechará la existencia de sucesos (Thiesse, 1981: 134).

Reflexionando sobre la posibilidad de que el origen de la novela folletinesca pudiera proceder de los sucesos, Thiesse (1981: 135) constata que si es verdad que novelistas realistas y naturalistas recurren a menudo al suceso, no es menos cierta la tentación de los periodistas de dar a sus sucesos un toque literario. Es más, el interés del lector de sucesos se produce en la medida en que éstos suscitan una identificación entre él y el héroe criminal o la víctima. Más adelante, siguiendo con la comparación fait divers/roman feuilleton llega a decir Thiesse (1981: 136):

si le roman-feuilleton peut susciter l'illusion réaliste, ce n'est point tant pour petits effets de réel que parce qu'il présente un univers fictif comme le fait divers narre la réalité.

Todos los estudios anteriores están imbricados no sólo por el marco histórico elegido, sino porque desde diversos enfoques y puntos de partida, en dichas investigaciones las conclusiones se hallan hermanadas. Ya sea desde el estudio de las causas célebres de Pitaval o Meissner, ya desde las historias trágicas de Bandello o Rosset, ya desde las relaciones y hechos probados de las publicaciones de la época o desde los relatos de Dufresny, las anécdotas o incluso el folletín, lo cierto y común es que nos situamos ante determinados relatos de verdad que habían sido arrinconados a un cuarto oscuro lejano de lo entitativamente literario. Ahora bien, todos los autores anteriores observan en dichos relatos una pretensión de verdad reclamada desde las técnicas de esforzada situación espacial y local, que no otra cosa es la hipotiposis. Por otra parte, se constata un interés social por estos pedazos de realidad, lo que lleva a una construcción de las mismas a base de una imitación de las imitaciones vigentes como la novela trágica, etc. Es, precisamente, esta imitación de imitación (vertiente quintilianista de la lectura clásica como imitación, Cabada Gómez, 1992) la que hace posi-

15 Cfr. Ferraz Martínez (1992: 1184). Por otra parte, ya aludió Barthes (1962: 226) a la inmanencia del suceso: «literariamente son fragmentos de novelas». El hecho de que «algunos sucesos se desarrollen en varios días (...) no rompe su inmanencia constitutiva, ya que implican una memoria extremadamente corta». 
ble el parentesco entre suceso y ejemplo, suceso y pliego de cordel, suceso e historia trágica, suceso y causa célebre, suceso y folletín, etc., como quiera que todas estas formas concebidas como narraciones de lo real histórico, poseen la función utilitaria y pedagógica de la moraleja y la función lúdica del entretenimiento. Con estas dos funciones claramente señaladas, nos hallamos ante el prodesse et delectare que define la lectura literaria clásica (Cabada Gómez, 1994). De otro lado, la lectura de la verdad como verosímil es la piedra de toque de todas las formas anteriores y cuestión primordial de este artículo, que pretende demostrar esto mismo en lo que concierne al suceso como forma establecida de relato. La elección del lector de discernir lo histórico de lo literario es, a nuestro juicio, un elemento de primer orden ofrecido por estos autores, que hace posible distinguir una lectura histórica de la crónica de sucesos en tanto comunicación (verídica) y una lectura literaria del suceso criminal en tanto literatura (verosímil).

\section{Referencias bibliográficas}

Aubague, L. (1980). La Revue mexicaine Alarma!: Discours, Imaginaire et Société (Propositions d'approche du Fait Divers). Tesis Doctoral. Universidad Paul Valéry-Montpellier III (inédita).

AUCLAIR, G. (1963). «Fait divers et pensée naive». Critique, 197, 893-907.

- (1966). «Meurtre, inceste et énigme. Étude comparée de presse». Revue Française de Sociologie VII, 215-228.

- (1970). Le Mana Quotidien. Structures et Fonctions de la Chronique des Faits Divers. Paris: Anthropos, 1982, 2. ${ }^{\mathrm{a}}$ ed. aumentada.

BARTHES, R. (1962). «Structure du fait divers». Médiations. En Essais Critiques, 1964 (versión española: Barcelona: Seix Barral, 1967, 225-236).

- (1968). «L'éffet de réel». Communications 11, 84-89.

Botrel, J. F. (1993). Libros, Prensa y Lectura en la España del siglo XIX. Madrid: Pirámide, Fundación Germán Sánchez Ruipérez.

Burgelin, O. (1974). «Los Sucesos». En La Comunicación de Masas, 98-103. Barcelona: A.T.E.

CABADA GÓMEZ, M. (1980). Para una Teoría de la Lectura Literaria. Anejo 1, vol. II de Senara. Vigo: Colegio Universitario.

- (1981). «Masificación de la forma de lectura burguesa: carácter residual y palabrista de la literatura». Senara, III, 253-287.

- (1982). El rendimiento de la literatura según la forma de lectura. Anejo III, vol. IV de Senara. Vigo: Colegio Universitario.

- (1989). El MitoLiteratura. Introducción a la teoría mitológica de la literatura. Santiago de Compostela: Milladoiro. 
- (1992). «Francisco Ayala, lector paradójico». En Francisco Ayala. Teórico y Crítico Literario, A. Sánchez Trigueros y A. Chicharro Chamorro (eds.), 83-92. Granada: Diputación Provincial.

- (1994). Teoría de la Lectura Literaria (I. Frente a la lectura histórica). Madrid: Altorrey.

Caro Baroja, J. (1969). Ensayo sobre la Literatura de Cordel. Madrid: Taurus, 1990.

- (1986). Realidad y Fantasía en el Mundo Criminal. Madrid: C.S.I.C.

Christin, P. (1973). Le Fait Divers, Littérature du Pauvre. Une étude d'un type de récit littéraire: le fait divers. Tesis Doctoral dirigida por Robert Escarpit. Universidad de Burdeos III (inédita).

FAVRE, R.; SGARD, J.; WeIL, F. (1978). «Le Fait Divers». En Presse et histoire au XVIII ème siècle: l'année 1734, P. Rétat y J. Sgard (eds.), 199-225. Lyon: Ed. C.N.R.S.

FERRAZ MARTf́neZ, A. (1992). La novela histórica contemporánea anterior a Galdós (de la Guerra de la Independencia a la Revolución de Julio). Madrid: Universidad Complutense.

FERRERAS, J. I. (1972). La Novela por entregas (1840-1900). Madrid: Taurus.

- (1973). Los orígenes de la Novela Decimonónica (1800-1830). Madrid: Taurus.

FRANDON, I. M. (1984). «Fait Divert et Littérature. En marge d'une exposition». Revue d'Histoire Littéraire de la France 4, 84, 561-569.

García de EnTERría, M. C. (1973). Sociedad y Poesia de Cordel en el Barroco. Madrid: Taurus.

- (1983). Literaturas marginadas. Madrid: Playor.

Hermoso, B. (1992). «Barba Azul, rehabilitado». El Mundo, martes, 10 noviembre, 26.

JeChova, H. (1980). «Vers la Littérature des Faits Divers». Cahiers de l'U.E.R. Froissart (Recherches en Lettres et Sciences) 4, 3-18.

LECERF, M. (ed.) (1981). Les Faits Divers. France: Larousse.

LEVER, M. (1979). «De l'information à la nouvelle: Les Canards et les Histoires tragiques de François de Rosset». Revue d'Histoire Littéraire de la France 4, 79, 577-593.

LÜSEBRINK, H. J. (1980). «Les crimes sexuels dans les causes célèbres». Dixhuitième siècle 12, 153-162.

MARCO, J. (1977). Literatura popular en España en los siglos XVIII y XIX. (Una aproximación a los Pliegos de Cordel). Madrid: Taurus.

Merleau-PonTy, M. (1960). «A propósito de los Sucesos». En Signos, 381385. Barcelona: Seix Barral, 1964.

Monestier, A. (1982-1983). Le Fait Divers. Catálogo del Museo Nacional y Tradiciontes Populares. Ministerio de Cultura de Francia: Éditions de la Réunion des Musées Nationaux.

- (1988). Los grandes casos criminales. Madrid: Ediciones del Prado, 1992.

MoureaU, F. (1978). «Fiction, Narrative, Nouvelles et Faits Divers au début du XVIII' siècle: L'exemple du Mercure Galant de Dufresny». Cahiers de l'U.E.R. Froissart. Recherches en Lettres et Sciences Humaines 3, 126-134.

- (1980). «Sade avant Sade». Cahiers de l'U.E.R. Froissart. Recherches en Lettres et Sciences Humaines Valenciennes 4, 19-28.

NIES, F. (1986). «Nouveaux genres littéraires en France à l'époque du papier continu». Romantische Zeitschrift für Literaturgeschichte 10, 184-196. 
Rimbault, C. (1981). La Presse Féminine de Lange Française au XVIII ème siècle. Place de la femme et Système de la Mode. Tesis Doctoral. École des Hautes Études en Sciences Sociales (inédita).

Ro(BERT) MI(CHEL) (1962). Histoire de cinq siècles des Faits Divers. Milán: Port Royal.

SCHULMANN, F. (1971). «Regard sur le Fait Divers». Esprit, 244-252.

SEguin, J. P. (1956). «Les Canards de Faits Divers de Petit Format en France au XIX siècle». Arts et Traditions Populaires IV, 1, 30-45; 2, 113-135.

- (1959). Nouvelles à Sensation. Canards du XIX siècle. París: Armand Colin.

- (1965). Physiologie du Canard. París: Flammes et Fumées.

- (ed.) (1982-1983). Les Canards de $19^{e}$ siècle. Fascination de Fait Divers. Catalogue de l'éxposition 9 novembre 1982/30 janvier 1983. MuséeGalerie de la SEITA.

SerRano De SANTOS, L. (1994). Lectura Paraliteraria del Suceso Criminal. Tesis Doctoral. Universidad Autónoma de Madrid (e.p.)

SGARD, J. (1974). «La littérature des causes célèbres». Melanges Fabre: Approches des Lumières, 459-470.

SORBIER, F. (1983). Récits de Gueuserie et Biographies Criminelles de Head à Defoe. Berne, Franfort, New York, Nancy: Lang.

Sullerot, E. (1970). En Entretiens sur la Paralittérature, Arnaud, Lacassin, Tortel (eds.), París: Plon.

ThIESSE, A. M. (1981). La Littérature Populaire en France (1900-1920). Tesis Doctoral. Universidad de París III (inédita). 